\title{
The Aura of Opera Reproduced: Fantasies and Traps in the Age of the Cinecast
}

\author{
João Pedro Cachopo \\ (Universidade Nova de Lisboa)
}

\begin{abstract}
Aiming to contribute to an ongoing debate on the relationship between opera and screen media, my article begins by posing a number of questions about the aesthetic and political implications of technological reproduction. I then examine and critique a paradox that pervades our media-saturated culture - namely, that the remediation of musical-theatrical works is often treated as a means of enhancing, rather than of questioning, a sense of authenticity, uniqueness, and presence. This in turn leads me to an analysis of three objects (and three fantasies) in which this paradox, which is bound up with a strange blend of nostalgia and an urge for excess, takes on paradigmatic form. I conclude with a critical reflection on the challenge inherent in recording and broadcasting operatic stage productions. Throughout, I aim to suggest ways of avoiding a fetishization of liveness without, however, falling into another trap - the simple dichotomization of liveness and mediatization.
\end{abstract}

\section{Chronicle of a Demise Foretold}

What are the aesthetic and political consequences involved in the remediation of opera? How does the possibility of translating a musical-theatrical artwork from the medium of stage to the medium of film, video, or television impact its production and reception? Does the audiovisual reproduction of opera entail a democratization of the experience of the genre? Does it contribute to the "decline of aura"-bridging the distance between audience and spectacle, and thus giving rise to new forms of appropriation — as a Benjamin-minded observer might expect and hope? ${ }^{1}$

In view of the diversity of practices and objects about which these questions may and should be raised, the first thing to acknowledge — an acknowledgment that is not to be mistaken for a rhetorical display of caution - is that a single, unambiguous response is unattainable. There cannot be a unique answer to these questions because the relationship between categories and objects is mutable and diverse. Nowadays, and for that matter since the emergence of synchronized audiovisual media, opera can be not only staged but also filmed. Besides, new operas have been composed for TV, a handful of them were originally conceived as films, and a few even more recent ones transgress the boundaries between performance, installation, and new media art. To complicate matters further, significant changes have also occurred in the way traditional opera is presented on stage. In fact, besides the multiplication of cameras and screens in new productions, it is now common for operas to be staged with an eye to their future recording or broadcast. DVD and Blu-ray have long become the most common forms through which stage productions become globally known and gain a reputation. Whether consciously or not, directors bear them in mind while honing their stagings to be as "camera-ready" as possible. This tendency has been exacerbated over the last decade as the opera cinecast phenomenon became prominent. $^{2}$

One thing is nonetheless clear about the technological reproduction of opera: the proliferation of mechanical and digital techniques to create copies is mirrored by a plethora of discourses commending the virtues of mediatization. Their rhetoric can be quite ambiguous, if 
not paradoxical. Indeed, the emphasis on, or even the parti pris for copying does not necessarily entail the questioning of originality. The copy may well be praised for its capacity to underline the characteristics of the original; that is, mutatis mutandis, the film or the video of an opera may well be valued for being able to bring the authenticity of the original to the fore. From this perspective, the task of reversing Platonism - as Nietzsche would have put it - might be harder than one thinks. For the cornerstone of Platonism, as Deleuze points out in Logique du sens, is not the separation between the original and the copy, but the separation - and the urge to attain a clear-cut distinction - between the "good" and the "bad" copy: the former aimed at resembling the original; the latter indulging in deviations and detours. $^{3}$

These reflections are germane to the debate on the remediation of opera. They find echoes in the work of theorists and scholars from various disciplines. Jay Bolter and Richard Grusin, whose work has become central in this debate, focus on what they call the "double logic of remediation." With this concept they seek to account for the entanglement of two contrasting, yet compatible, trends that characterize our increasingly mediated culture: the call for immediacy (for transparency in mediation) and the call for hypermediacy (for the multiplication of media), which would ultimately converge in the "desire to get past the limits of representation and to achieve the real" ". Though thoughtful, their theoretical endeavor falls short of critically addressing the underlying motivations of this urge "to achieve the real." The possibility that this urge be also a manifestation of nostalgia is neither explicitly nor implicitly addressed.

When it comes to disclosing the untold motives behind the debate on mediatization and liveness, Philip Auslander takes an important step further. In Liveness: Performance in a Mediatized Culture, he draws attention to the flaws behind the ontological argument through which scholars have presented live performance as a locus of resistance within a world increasingly dominated by potentially alienating media. However different, Auslander suggests, live and mediatized performances cannot be distinguished on ontological grounds. In support of this claim, Auslander describes how the notion of "live" only emerged in the course of the technological developments leading from the first recording practices to the advent of digital technologies of reproduction, distribution, and communication. The surplus of authenticity associated with liveness is thus revealed as a mirage.

Auslander's analysis implies that an emphasis on liveness is not only theoretically flawed, however; it is also politically ambivalent. On the one hand, the valorization of liveness stems from an attempt to resist the advancement of late capitalism, proceeding from an assumption that the principle of exchange and the logic of reproduction reinforce each other. On the other hand, liveness also, and perhaps involuntarily, hinders the "sense of equality" that Benjamin regarded as the main promise of technological reproduction.

Consider the following passage in Auslander's argument:

I return now to Benjamin's observation on what he called "contemporary perception" and its hunger for reproductions. "To pry an object from its shell," he writes, "to destroy its aura, is the mark of a perception whose 'sense of the universal equality of all things' has increased to such a degree that it extracts it even from a unique object by means of reproduction [...]. I have tried to suggest here that this is exactly the state in which live performance now finds itself: its traditional status as auratic and unique has been wrested from it by an ever-accelerating incursion of reproduction into the live event. Following Benjamin, I might argue that live performance has indeed been pried from its 
shell and that all performance modes, live or mediatized, are now equal: none is perceived as auratic or authentic; the live performance is just one more reproduction of a given text or one more reproducible text. [...] This situation represents the historical triumph of mechanical (and electronic) reproduction (what I am calling mediatization) that Benjamin implies: aura, authenticity, and cult value have been definitively routed, even in live performance, the site that once seemed the last refuge of the auratic. ${ }^{5}$

As much as I sympathize with Auslander's overview of Benjamin's ideas, I also think that he is far too optimistic in asserting that the complete emancipation of the copy or, as he puts it, the "triumph of mechanical (and electronic) reproduction" has indeed occurred. Instead, I would claim, and for reasons that his book helps illustrate, that the charm of aura, despite the multiplication of copies, is far from fading away. Today we can witness a proliferation of objects and practices in which an emphasis on technological reproduction coexists with an infatuation with originality and authenticity. In many of them, if I am allowed to bring Benjamin and Deleuze together, the valorization of copies goes hand in hand with the fetishizing of aura, inasmuch as one is still invited to distinguish, overtly or covertly, between "good" and "bad" copies on the basis of whether or not they prove able to render the presence and impact of an original. Aura, that is to say, seems to have survived and adapted to a culture in which technological reproducibility became the rule.

In order to investigate this claim in more detail, I will focus on three, apparently unrelated, objects: a recently released DVD \& Blu-ray box set of three "live films" of operatic hits (Tosca, La Traviata, and Rigoletto), conceived and produced by Andrea Andermann; an exhibition (held at La Seine Musicale in Paris in the Fall of 2017) and a film documentary about Maria Callas, integrated in Tom Volf's project "Maria by Callas"; and, finally, Peter Gelb's The Met: Live in HD initiative.

\section{Live from Rome, Paris, and Mantua}

Released in 2016, Andermann's box set contains filmed versions of Tosca, Rigoletto, and La Traviata that were filmed in selected locations in Rome (1992), Paris (2000), and Mantua (2010). These reenactments of Puccini's and Verdi's operas were originally conceived, as Andermann put it, as "live films". Their specificity, if one compares them to conventional opera films, is twofold. Firstly, they were not only shot but also broadcast live to TV audiences in more than 100 countries around the world. Secondly, neither the locations nor the times were irrelevant. Indeed, the three operas were performed and recorded as a live television transmission in the settings and at the times prescribed by libretto and score. This worked particularly well with Tosca, directed by Patroni Griffi, as Puccini chose as a background for this opera three iconic buildings in Rome: the church of Sant'Andrea della Valle, Palazzo Farnese, and Castel Sant'Angelo. As Andermann explains the aims for his "electronic Tosca":

This performance of Giacomo Puccini's opera Tosca was conceived specifically in terms of a live television transmission in "the settings and at the times of Tosca." So the singers perform each act in the spectacular monumental buildings prescribed by the composer: midday at Sant'Andrea della Valle, the same evening at the Farnese Palace and the following dawn at Castel Sant'Angelo. Three appointments, each lasting about 45 minutes, between a Saturday and Sunday, to constitute "a weekend in Rome with Tosca." The Maestro conducts his orchestra in another location, with the various 
elements linked by closed-circuit TV. In this way television, by virtually taking Puccini's opera apart and putting it together again, gains in stature, both technically and creatively. But all this with total respect for the original [my emphasis], following, in a certain sense, the scrupulous research in Rome that Puccini himself carried out over a number of years. And again it is television which makes it possible for this unique production of Tosca to be broadcast live to the entire world: a "live film," therefore, employing the various forms of communication available to contemporary "Audiovisual Man.",6

This brief description contains important elements that shed light on the letter and spirit of the project. On the one hand, it highlights the complexity and the virtues of technological reproduction. Neither the filming nor the transmission would be possible without the support of complex and innovative forms of communication, recording, and broadcast. They are the condition sine qua non of this unprecedented encounter between an "electronic Tosca" and an "audiovisual man." On the other hand, all is done with total respect for the original. The care and effort invested in the gimmick (of spatial and temporal exactitude) shows how deeply a quest for authenticity determined this (copy of) Tosca in the settings and at the times of (the original) Tosca.

What exactly originality means in this context deserves further analysis. On one level, the original of these reproducible operas is nothing but the operatic genre as such. From this perspective, the challenge is to put the medium of television at the service of the genre of opera. The goal pursued can thus be equated with what Andermann calls "a symbiosis between the diaphragm of the singer and that of the camera." In this respect, these "live films" of Tosca, La Traviata, and Rigoletto are no different than traditional opera films in their more or less accentuated attempt to render the "operaticness" of their models. By the same token, this understanding of originality falls short of doing justice to the singularity of Andermann's idea. The notion of "original" refers not only to opera in general but also to this or that opera in particular. Now, Tosca, La Traviata, and Rigoletto are taken not only in the theatrical-musical integrity of their scores and librettos, but also in the spatial-temporal singularity of their dramas, as when Plácido Domingo, playing the role of Caravadossi, sings "E lucevan le stelle" on the roof of Castel Sant'Angelo against the background of Saint Peter's Basilica shortly after dawn (figure 1).

The medium of film does more than simply allow for a displacement of opera from stage to screen. It also returns Tosca to the original Rome of Puccini's imagination, thus suggesting that a deeper degree of authenticity can thereby be attained. This authenticity is no longer the hic et nunc of a stage production of Tosca, but the hic et nunc of the "authentic" locations and the "authentic" times within which the tragedy unfolds. We are invited to witness the miracle of a copy that is potentially better than the original - better, however, not as a copy that goes beyond the original, but as a copy that reflects the original to the point of penetrating it in search of a deeper truth. A stage production of Tosca offers the physical copresence of performers and audiences in the same space at the same time. Andermann has something else in mind: he proposes an "auratic" experience of the tragedy in the "original" locations at the "original" times. The loss involved in trading physical co-presence for virtual spatial-temporal coordination seems irrelevant compared to what one gets in return: the fantasy of a fiction that is more authentic than the reality of a live performance. ${ }^{8}$ 


\section{Live from the World of the Dead}

The quest for a truth through and beyond fiction is equally present in the project Maria by Callas. Conceived by Tom Volf, this multimedia enterprise-involving a documentary film, an exhibition, three books, and (at least up until recently) a collection of recordings - seeks to reunite the personal and the artistic sides of Maria Callas so as to "discover the last of the divas, introducing herself for the first time in the first person through exceptional documents, kept secret for over 40 years by her acquaintances from the four corners of the world." 9 Once again, the reality of reproduction and mediation - and the multiplication of perspectives associated with it - is underlined. At the entrance of La Seine Musicale, where the exhibition was held in the fall of 2017, the visitor was welcomed by a sculptural hydra of multiple screens, where video recordings of Maria Callas's performances and interviews were juxtaposed (figure 2). With its intimations of dispersion and fragmentation, this sculpture set the tone for the entire exhibition, which gathered private films on Super 8 and 16mm, unpublished photos, bootleg recordings, intimate letters, and lost interviews.

At the same time, the emphasis on technological reproduction - the attachment to copies allowing for the recollection of unique moments in the live and career of the divawent hand in hand with an intimation that the ultimate purpose of bringing together such multiple traces was to find the way back to the original: the singularity of Maria Callas. Indeed, one of the most striking features of the discourse around this project, in which expressions such "landmark," "finally," or "for the first time" abound, consists in its selfpromotion as an absolutely new attempt to discover the "woman [Maria] behind the legend [Callas]," as if the attempt to grasp the truth of the individual behind the myth of the artist were not a worn-out trope (especially in the case Maria Callas) ${ }^{10}$. True, the documentary avoids using words said or written by anyone but Maria Callas (read by Fanny Ardant, in the French version, and by Joyce DiDonato, in the English one), which is neither irrelevant nor devoid of interest on account of what it reveals about the life and career of Maria Callas. However, acknowledging the merits of the documentary should not make us forget that any documentary, by virtue of being one - that is, inasmuch as it is an exercise of assemblage and collage - presupposes and constitutes a reading. In the case of Maria by Callas, this reading is Tom Volf's, not Callas's, no matter how prominently her voice is featured in the film, and no matter how insistently its marketing stresses the miraculous virtues of transparency and authenticity.

If we take a closer look at the entire project, we might nonetheless come to realize that its innermost goal is not simply to grasp the truth about Maria Callas. It is also, in fact crucially, to reveal the point in which truth and myth illuminate each other - at least, we are led to believe, in her case. In this regard, the title of the project ("Maria by Callas") is revealing. What is at stake is not so much the "truth" about Maria regardless of the "myth" of Callas (which would justify a much less catchy title such as "Callas by Maria"), but the truth about Maria that calls for a different kind of myth: not the legend of the singer (the idiosyncratic, if not whimsical diva) but the legend of the woman, whose joys and sorrows, passions and disillusions, life and death resemble the destiny of the characters she embodied as an artist. "Her extraordinary life," it is also stated, "reads like a novel or a tragic opera." In the end, it is the aura of the exceptional artist - whose unparalleled gifts, convoluted career, and tragic life seem all the more unique as one realizes that Maria Callas was a simple woman too- that is once again reinforced. 


\section{Live from The Metropolitan Opera House}

The merits of technological reproduction, including the wonder of bringing "liveness" and "mediatization" together, is also at the core of the discourse on opera cinecasts. Launched by Peter Gelb in 2006, The Met: Live in HD, the most famous among these series of live transmissions from opera houses to movie theaters, has initiated a new era in the history of the Metropolitan Opera as well as, according to some, a new paradigm in opera reception. The fact that so many people around the world - not exactly from any location in the globe but certainly from regions far removed from the geographical horizon of a New Yorker operagoer - are now given the opportunity to attend the screenings of Met's productions throughout the season is indeed worth emphasizing. In addition to this "democratizing" virtue, the potentialities of the medium should not be forgotten: video allows for all kinds of nifty camerawork, from close-ups to full-screen images and tracking shots from the lip of the stage, which yield perspectives that no spectator in the theater could ever aspire to see from their seat.

The above is true whenever a camera is used and therefore applies to both live transmissions of stage productions and studio-filmed productions. However, contrary to opera films, in which the potential inherent in the medium is often used to stress that opera is henceforth independent from the stage, opera cinecasts tend to underline the theatrical characteristics of opera as a multimedia art form meant to be performed live. ${ }^{11}$ Once again, it seems clear that the logic of the (reproducible) copy is put at the service of the original (experience). This is not without political implications, which, in the case of the Met, come with an institutional twist: the broadcasts are not only a reproduction of one particular opera or of one particular production of that opera; nor are they meant to be about the operatic experience in general. Instead, they seek to reproduce, first and foremost, the attendance of a live performance at the Metropolitan Opera House. In his analysis of what he calls the "institutional dramaturgy" of The Met: Live in HD, James Steichen honed in on this claim:

The broadcasts take not just the individual opera, but the Metropolitan Opera, as their main product - the opera is inseparable from the Opera. The broadcasts work ultimately in service not of opera (or even the director or performance), but of the institution, and the original performance and its presenter gain even more cachet. Through this remediatization, the Met can capitalize on new forms of exhibition value and in turn reinvigorate the exchange value of its original product. In his bid for inclusivity, therefore, Gelb has to make a subtle case for exclusivity, as well. ${ }^{12}$

This twofold strategy, in which the live and the mediatized are bound together with a view to captivating a new audience without alienating the traditional one, is even more intricate than it would seem. To compensate for a loss of presence and glamour, the cinematic experience must also be presented as extraordinary in itself. In the case of The Met Live in HD, this overcoming of the original by the copy is due less to videographic experimentation, than to a further component that fully complies with the marketing strategy described by Steichen: the special features. In a sense, attending a live broadcast of a performance from the Met is not only almost as good as attending the same performance at the Met. It is also better. In addition to visually "enlarging" and "expediting" the view of the performance, thanks to "the magic of "numerous robotic cameras,", "13 cinecasts also grant access to what is happening beneath, behind, and beyond the stage itself. 
The thrill, before and during the performance, in the orchestra pit and backstage becomes palpable (figure 3). The artists are interviewed, while the practical movements and relaxed clothing of technicians provide the background with some couleur locale (figure 4). One also gets to know more about the peculiarities of the productions as pre-recorded videos of rehearsals are also shown (figure 5). In a way, it is as if the fourth wall were broken, though with motivations that are at the antipodes of Brecht's. In fact, the means of operatic production are revealed, not to destroy the illusion of the spectacle, but rather to transform this revelation into a spectacle in itself. Nothing is hidden, and yet everything looks as shiny and opaque as a gigantic puppy by Jeff Koons. In the end, the thrill associated with operagoing (a space-related fetish) yields to the excitement of following a live event (a timerelated fetish). The latter is a two-in-one live event: a mediatized/live performance and a mediatized/live making-of of that performance. Both are fantasized as 'drastic' experiences: we know very well that we are not there, just as we suspect - we cannot help but surmisethat the singers are not being asked and answering that question right now, but still we believe. ${ }^{14}$ Or, at least, we enjoy the show, along with the aura of unpredictability that surrounds any live spectacle, as if we believed that anything onstage or backstage might happen.

In their ambition and stubbornness, and regardless of their unequal successes, Andrea Andermann, Tom Volf, and Peter Gelb have something in common: they are pragmatic daydreamers. They all nurture and pursue a fantasy with quite concrete outcomes in mind. They devise an operatic-institutional storyline, in which technological reproduction drives the action and the copy plays the role of the protagonist. Yet this role is invariably paradoxical: these copies are at once overtly adventurous and secretly nostalgic. In other words, they do not shy away from presenting themselves as copies: they are the proud offspring of reproduction, recording, and mediatization. And yet, not only do they honor the spirit of the original, they also attempt, in subtle, yet recognizable ways, to radicalize it. They are, so to speak, more Platonic than Plato. They wish to achieve a real more real-more authentic, more unique, more drastic - than reality itself.

It goes without saying that this "real more real than reality" is a far cry from the reality of ideas that Plato had in mind. It is a real whose materiality and contingency are unapologetically affirmed and inflated — via the same technologically driven mode of excess that Jameson famously declared to be at the core of the postmodern sublime. ${ }^{15}$ The reason why it still makes sense to speak of Platonism in this context is that this real, albeit eccentric and decentered, continues to exert its authority over the copy into swearing allegiance to the original. This original might be nothing but a fantasy, or, as Auslander puts it, it might be no longer possible to distinguish between the "authenticity" of liveness and the "fakeness" of mediatization. However, the charm of originality - the aura of the original rather the original itself - persists. It is still with an eye to the values of authenticity, singularity, and presence that the "good" copy proudly distinguishes itself from the "bad" copy in the age of the digital reproduction of the work of art.

\section{Between Fantasies and Traps}


In the remainder of this article, I consider the phenomenon of opera cinecasts within larger debates on the remediation of opera by video and film, aiming to anticipate some of the traps that one might encounter as one seeks refuge from the fantasies scrutinized above. I will advocate a close liaison between the "remediating video" and the "remediated staging," which at first sight might seem in contradiction with the critical appraisal of the fascination with originality that dominates the first part of this essay. I want make clear that this is not the case. No contradiction emerges from commending, on the one hand, the articulation between dramaturgy and videography and, on the other hand, rejecting the myth of fidelity (to the "original"), if only because all and every staging is always already (as a "copy") an exercise of potential infidelity. My main point will be that the true opposition is not between liveness and mediatization but rather between a "traditional" and a "critical" way of fostering their interaction.

As we have seen, a central reason why the Met HD series represents a challenge for critics and scholars lies in the paradox in which its rhetoric is embedded - a paradox that praises technological reproduction and remediation while also nodding at the charm, the superiority, and the uniqueness associated with the real thing (attending a live performance at the Met). ${ }^{16}$ This paradox puts pressure on scholars and critics who, on the one hand, reject the ideology of authenticity associated with a parti pris for live performance, but, on the other hand, are unwilling to praise The Met: Live in $H D$ as the ultimate wonder in the admirable new world of digital technology. The question arises whether there are ways of exploring the potentialities of technological reproduction without ending up reproducing the rhetoric of presence and liveness or, put otherwise, whether a fixation on the original can be neutralized in aesthetically and politically meaningful ways rather than merely displaced or rebranded.

Some general observations are in order. When we talk about opera cinecasts, we actually mean - neither always nor necessarily, but in the vast majority of cases - the broadcasts of stage productions of pre-existing operas. This is the case for the Metropolitan Opera House as well as for the other opera companies around the world that have developed similarly-minded projects (such as the Royal Opera House, the Opéra de Paris, or La Scala). ${ }^{17}$ In their historical, social, and institutional complexity, the reasons behind the relatively weak engagement with contemporary creation in the case of major opera houses would certainly be worth discussing, but stand too far removed from my concerns in this essay. For the sake of the argument, I will limit myself to recall Stanley Cavell's comment that "ours is not on the whole an age of awaiting the creation of new operas, but it is an age of awaiting the creation of new productions of operas, whose fame comes from what is in effect their new readings of, potentially, the entire heritage of opera." ${ }^{\prime 18}$ As a consequence, in the vast majority of cases, the audience is potentially as much interested in the staging and casting as in the opera being performed. In fact, this is true even in the sole instance in which the encounter with an opera necessarily coincides with the encounter with the staging (in the case of world premieres).

Under such circumstances, it is crucial to recognize that the task of filming the staging of an opera is a very particular one and cannot be equated with that of making a film of an opera. In fact, the latter has more in common with the staging of an opera than with the filming of the staging of an opera. Both the stage director (in a stage production) and the film director (in a film production) reinvent an opera, the difference being that the medium of such a reinvention is, in the former case, the "original" medium (the stage) and, in the latter case, a "derivative" medium (the film or the video). In both cases, however, the task of interpretation is inseparable from the prerogative of variance and deflection. Neither the stage director nor 
the film director is bound to faithfully reenact the "original" work, even if the "interpretation" of the stage director remains within the scope of the "original" medium while the film director is faced with the twofold challenge of both interpreting the opera and translating it into a new medium. In both cases, I would claim that the method is detour. Yet the detour also requires method: vision, creativity, and consistency. If a staging possesses such qualities, the video that remediates it cannot simply turn a blind eye and a deaf ear.

I am reminded of Benjamin's claim that "translations [...] prove to be untranslatable." ${ }^{19}$ When I first encountered this passage, I was writing an article in which I sought to bring Benjamin's insights on the "task of the translator" to bear on the discussion of opera films. What most interested me was the concept of "translatability" - the idea that a text is all the more translatable as it resists translation, thus forcing the translator to broaden the means of expression of the target language. I used this concept to propose ways of addressing and evaluating opera films that avoid assumptions that opera films should be either strictly faithful to the original medium or blindly obedient to the new one. ${ }^{20}$ What now seems more pertinent, however, is Benjamin's claim that his own considerations about the autonomy and relevance of translation do not apply to translations of translations. I would like to take his claim as a suggestion that our critique of the rhetoric of fidelity should adjust to different scenarios, and that we should be particularly cautious as to whether a staging, an opera film, or the video of a staging is under analysis.

In a cogently argued essay on live opera videos, Emanuele Senici quotes a blog commentary on the HD broadcast of Jürgen Flimm's Metropolitan Opera production of Strauss's Salome, in which an anonymous spectator expressed their dissatisfaction. "The cameras aren't showing what I would like to see," they wrote. "I would like always to see everything on the stage [...] exactly as a live audience sees it." ${ }^{21}$ For Senici, this complaint is typical of an ingrained resistance to remediation and technology, which goes hand in hand with a "mystique of the live event." 22 Though I agree with the main argument of his essay, according to which "the rhetoric of 'fidelity' that tends to dominate past and present discourse [on live opera videos]"23 should be overcome with the help of a yet-to-be-developed critical vocabulary, I also confess that, like the anonymous commentator, I too, quite often, feel frustrated by the experience of having a camera "think[ing] for me and decid[ing] for me where my interests lay." 24 This confession, however, does not betray a preference for broadcasts and recordings in which the live experience is reproduced as faithfully as possible. Instead, it is a response to videos that are indifferent or detrimental to the stagings they capture.

Jonathan Rosenbaum once admitted in a public lecture that, despite his admiration for Orson Welles's oeuvre, one of the reasons why he is not particularly fond of his Macbeth (1948) is that, in this feature, the frequency of low-angle shots teeters on the edge of mannerism. However fair or unfair this appraisal may be, it strikes me as a particularly fitting way to characterize several opera videos. In their attempt to make it new, they frequently descend into a caricature of cinematic experimentalism, endlessly repeating the same "innovative" clichés. At first glance, they seem to be at the antipodes of a "conservative" approach that shows the stage exactly as the audience would see it in the theater. The two strategies, however, eventually meet in one point: they similarly fail—as if theatrical "transparency" and cinematic "mannerism" were the Scylla and Charybdis of operatic videography - because they both depart from an a priori assumption as to whether a theatrical-looking or a cinematic-looking video should be preferred. 
Uffe Borgwardt's video of Kasper Holten's staging of Tannhäuser provides a good example of the latter approach. Numerous low-angle shots and close-ups punctuate the video with visually impactful markers (figure 6). Yet they follow one another in a rather monotonous, seemingly automated way. This is unfortunate, not the least because the staging asks for a different approach. Holten underscores the idea of writing: Tannhäuser is portrayed as a contemporary writer who feels divided between the stability of domestic life and the inspiration that only the thrill of passion and sexuality afford him. The bare legs of the frantic dancer on which the enraptured bard writes up his poetic ideas are shown in a close-up, yet this is as close as one gets to an exploration of the idea that prompts the staging (figure 7). Not only does the video constitute what for want of a better word I would call a mannerist attempt to emulate the cinematic larger-than-lifeness of operatic acting and singing, it also fails to enter in a dialogue with the staging itself. The two aspects are inextricably connected and their connection is what needs to be stressed: the problem is not that the video suggests a cinematic reading but that such a reading fails to render explicit, let alone convincing, its immanent relationship to the staging.

It is by no means a coincidence that both Senici's and Christopher Morris's attempts to illuminate the potentialities of opera videos focus on a production in which the interconnection between staging and video turns out to be decisive: Philippe Béziat's collaboration with Giorgio Barberio Corsetti and Pierrick Sorin in a production of Rossini's La pietra del paragone. ${ }^{25}$ Two aspects are worth underlining: first, that the video's success could not be achieved without "highlighting the range of manipulations at the video director's disposal and creating anything but the transparent impression of being there," 26 second, that these manipulations were already called for by the staging itself, which indeed "opens up unusual technical and aesthetic possibilities to video recording. ${ }^{, 27}$ Indeed, the video picks up where a purely theatrical staging could not go further. This is particularly discernible in the manipulation of spatial-temporal parameters associated with location, scale, and motion, bringing to another level the musical and theatrical playfulness of Rossini's opera, which the staging itself engages, explores, and radicalizes (figure 8).

Paradoxical as it may seem, if I'm allowed to allude to my title as I conclude my reflections, the aura of opera is exactly what is often reproduced today. From a critical perspective, it is crucial to disclose the fantasies that give expression to this paradox, while also debunking the myth of the original and underlining the value of the copy as detour, reinvention, and infidelity. Yet we should not be fooled by our own convictions. Even a stage production without the slightest recourse to digital technologies may be as effective as a critique of aura as the most complex videographic object. That is to say, the principle of mediatization - allowing for the dissemination of opera in various platforms, the multiplication of screens and cameras on stage productions, or the bid for cinematic effects in video recordings and broadcasts - does not, a priori, free opera from aura. It represents, however, a formidable chance to challenge the entanglement of opera and tradition. The point, therefore, is not to take sides in a dispute between liveness and mediatization - an assumption in which this discussion may easily get trapped - but to investigate the ways in which their interaction may enhance the critical role of opera in a media-saturated world that continues to be, despite rapid and profound changes in the cultural landscape, a profoundly conservative one. 
João Pedro Cachopo is a Marie SkŁodowska-Curie Fellow with a joint affiliation to the Universidade Nova de Lisboa and the University of Chicago. His research interests span the fields of musicology, opera studies, film and media studies, comparative studies, critical theory, and philosophy with a focus on issues of intermediality, spectatorship, and criticism. He is the author of Verdade e Enigma: Ensaio sobre a estética de Adorno (Vendaval, 2013), which won the First Book Award from the Portuguese PEN Club in 2014, and the coeditor of Rancière and Music (Edinburgh University Press, 2019). Currently, he is working on a monograph titled The Profanation of Opera: Music and Drama on Film. He wants to thank the anonymous reviewer for their insightful and helpful comments and suggestions. This article is part of a project that has received funding from the European Union's Horizon 2020 research and innovation programme under grant agreement No. 708601. ${ }^{1}$ These questions have been raised and discussed with increasing vigor over the last decades by a variety of scholars whose subjects of inquiry range from the subgenre of opera film to the remediation of stage performances, and the use of operatic music in cinema. See, for example, Jeremy Tambling, Opera, Ideology, and Film (Manchester: Manchester University Press, 1987); Marcia Citron, Opera on Screen (New Haven: Yale University Press, 2000); David Schroeder, Cinema's Illusions, Opera's Allure: The Operatic Impulse in Film (New York: Continuum, 2002); Michal Grover-Friedlander, Vocal Apparitions: The Attraction of Cinema to Opera (Princeton \& Oxford: Princeton University Press, 2005); When Opera Meets Film (Cambridge: Cambridge University Press, 2010); and Jeongwon Joe, Opera as Soundtrack (Farnham: Ashgate, 2013). The following collective volumes are also worth mentioning: Jeremy Tambling (ed.), A Night in at the Opera: Media Representations of Opera (London: John Libbey, 1994); Jeongwon Joe \& Rose Theresa (eds), Between Opera and Cinema (New York: Routledge, 2002); and Aude Ameille et al. (eds) Opéra et cinéma (Rennes: Presses Universitaire de Rennes, 2017). For an article-length synthesis, see Mervyn Cooke, "Opera and Film," in The Cambridge Companion to Twentieth-Century Opera, ed. Mervyn Cooke (Cambridge: Cambridge University Press, 2005), 267-290. For a discussion of the operatic inheritance of cinema, see Stanley Cavell, "Opera and the Lease of Voice," A Pitch of Philosophy: Autobiographical Exercises (Cambridge, MA: Harvard University Press, 1994), 129-169, and Mehdi Belhaj Kacem, Opera Mundi: La seconde vie de l'opéra, 1 (Clamecy: Éditions Léo Scheer, 2012).

${ }^{2}$ As Carolyn Abbate and Roger Parker point out in the very last chapter of their History of Opera, "staging is now often conceived with the cameras in mind, and sometimes privileges the camera above the view from Row M in the stalls." Carolyn Abbate \& Roger Parker, A History of Opera (New York: Norton, 2015), 552.

3 "We are now in a better position to define the totality of the Platonic motivation: it has to do with selecting among the pretenders, distinguishing good and bad copies or, rather, copies (always well-founded) and simulacra (always engulfed in dissimilarity)." Gilles Deleuze, "Plato and the Simulacrum," in The Logic of Sense, trans. Mark Lester (New York: Columbia University Press, 1990), 253-279 (256-7); "Platon et le simulacre," in Logique du sens (Paris: Minuit, 1969), 292-306 (296).

${ }^{4}$ Jay Bolter and Richard Grusin, Remediation: Understanding New Media (Cambridge, MA: MIT Press, 1999), 53

${ }^{5}$ Philip Auslander, Liveness: Performance in a Mediatized Culture, 2nd ed. (London: Routledge, 2008), 55.

${ }^{6}$ Andrea Andermann, "Electronic Tosca," in the booklet of 3 Live Films: Rigoletto in Mantua, La Traviata in Paris, Tosca in Rome, Blu-ray, Naxos NBD0052-54 (2016), 14

${ }^{7}$ Andrea Andermann, quoted in ibid., 13.

${ }^{8}$ For a sympathetic view of Rigoletto in Mantua, the third and last of these "live operas," see Christopher Morris, "The Mute Stones Sing: Rigoletto Live from Mantua," TDR: The Drama Review, Vol. 59, No. 4 (Winter 2015 [T228]), 51-66. Bringing the site-specificity of the project into focus, Christopher Morris suggests that the encounter of live performance and dead locations (among which the Palazzo del Te, the Palazzo Ducale, and the Teatro Bibiena di Mantova) also provides an opportunity to unsettle age-old binaries such as animate/inanimate, presence/absence, and inert object/enlivened subject that are part and parcel of the operatic tradition.

${ }_{9}^{9}$ In http://www.mariabycallas.com/ (accessed April 24, 2018).

${ }^{10}$ A quick search on Google would easily lead the reader to titles such as Maria Callas: The Woman Behind the Legend (1981) by Arianna Stassinopoulos or The Unknown Callas (2001) by Nicholas Petsalis-Diomidis. That having been said, it is as also intriguing and noteworthy that a number of multimedia projects have recently turn their attention to Maria Callas, including - to give two widely different, yet probably somehow connected examples- the "Callas in Concert" shows, in which the audience is invited to see and listen to digitally manipulated reproductions of the dead singer's voice and figure (https://basehologram.com/productions/mariacallas), and Marina Abramovic's The Seven Deaths of Maria Callas opera project

(https://www.staatsoper.de/en/productioninfo/7-deaths-of-maria-callas.html), which is scheduled to premiere on April 11, 2020 at the Bayerische Staatsoper.

${ }^{11}$ See Marcia Citron, Opera on Screen (New Haven, CT: Yale University Press, 2000), esp. chapter 5.

${ }^{12}$ James Steichen, "The Metropolitan Opera Goes Public: Peter Gelb and the Institutional Dramaturgy of The

Met: Live in HD," Music and the Moving Image 2, no. 2 (Summer 2009): 29.

${ }^{13}$ James Steichen, "HD Opera: A Love/Hate Story," The Opera Quarterly 27, no. 4 (Autumn 2011): 445.

${ }^{14}$ Regarding the question of whether or not the interviews are scripted, see ibid. $447 \mathrm{ff}$. 


\footnotetext{
${ }^{15}$ Fredric Jameson, "The Cultural Logic of Late Capitalism," in Postmodernism, or, The Cultural Logic of Late Capitalism (Durham: Duke University Press, 1997 [1991]), 1-53 (esp. 37-8).

${ }^{16}$ In a consideration of opera cinecasts, it is neither rare nor unjustified to pay special attention to The Met: Live in $H D$. After all, Peter Gelb's initiative is probably the best known and most successful attempt to make opera accessible to a massively wide audience. Yet, in the light of the critical attention it has already received, it is also advisable to remind the reader that Met cinecasts represent only one instantiation of what is a complex, multilayered phenomenon, the many potentialities of which are often only partially recognized. Opera cinecasts do not even need to be live. There are also cases of non-live transmissions. Furthermore, the possibilities of accessing opera on-line are expanding in an extraordinary pace. Whist some of these other scenarios come with a loss of liveness, they still represent a means of being updated as to what is globally happening in the opera world.

${ }^{17}$ A quick glance at the history of the Met HD series will show that only once was this not the case. Among the more than 100 productions that were broadcast since 2006 only Tan Dun's The First Emperor (broadcast on January 13,2007) was the first and original production of a new opera. Even Thomas Adès's The Exterminating Angel, which is a fairly new opera and was seen in New York in the fall of 2017 in his original staging, had received its world premiere on July 28, 2016 at the Haus für Mozart in Salzburg.

${ }^{18}$ Stanley Cavell, "Opera in (and as) Film," in Cavell on Film, ed. William Rothman (New York: State

University of New York Press, 2005), 309.

19 "The Task of the Translator," trans. Harry Zohn, in Walter Benjamin, Selected Writings, Vol. 1: 1913- 1926, ed. Marcus Bullock and Michael W. Jennings (Cambridge, MA: Harvard University Press, 1996), 262; "Die Aufgabe des Übersetzers," Gesammelte Schriften, Vol. 4.1 (Frankfurt am Main: Suhrkamp, 1972), 20.

${ }^{20}$ Cf. João Pedro Cachopo, "Opera's Screen Metamorphosis: The Survival of a Genre or a Matter of Translation," The Opera Quarterly 30, no. 4 (2014): 315-329.

${ }^{21}$ Quoted in Emanuele Senici, "Porn Style?: Space and Time in Live Opera Videos," The Opera Quarterly 26, no. 1 (Winter 2010): 63.

${ }^{22}$ Ibid.

${ }^{23}$ Ibid., 64.

${ }^{24}$ Ibid., 63

${ }^{25}$ Emanuele Senici, "Porn Style?: Space and Time in Live Opera Videos," 70-78; Christopher Morris, "Digital Diva: Opera on Video," The Opera Quarterly 26, no. 1 (Winter 2010): 109.

${ }^{26}$ Morris, 109.

${ }^{27}$ Senici, 73.
} 